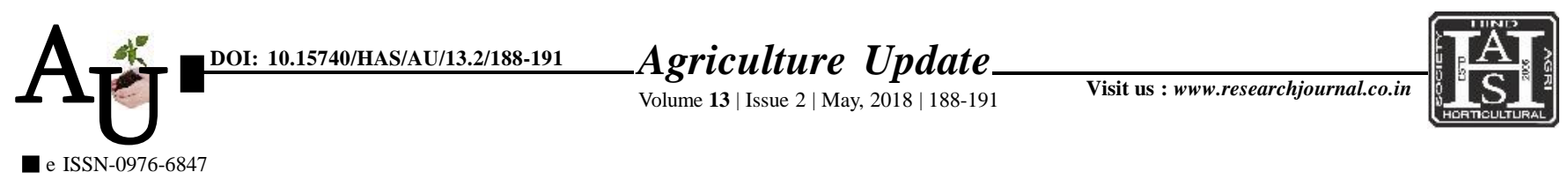

\title{
Research Article: Role of skill development and knowledge enrichment in the adoption of energy conservation practices
}

\section{Kulvir Kaur}

Article Chronicle: Received :

28.02.2018;

Revised :

27.03.2018;

Accepted :

12.04.2018

\section{KEY WoRDS:}

Adoption, Knowledge, Constraints, Energy conservation
Author for correspondence :

\section{Kulvir Kaur}

Department of Extension Education, Punjab Agricultural University, Ludhiana (Punjab) India

Email:kulvirkaur70@ pau.edu
SUMMARY : The present research on role of skill development and knowledge enrichment in the adoption of energy conservation practices was conducted in Hoshiarpur district of Punjab state. Fifty rural women were selected randomly from two villages. The data were collected by using structured interview schedule both before and after imparting knowledge and skill. Knowledge and skill was imparted through lectures and participatory demonstrations. Mostly respondents were found in medium age category, matric passed, agricultural background and medium income group. Mostly respondents adopted human energy conservation practices and lesser change in developing habits for judicious use of electricity was found among family members. Lack of interest was the main issue among respondents for non-adoption of heat energy conservation practices.

How to cite this article : Kaur, Kulvir (2018). Role of skill development and knowledge enrichment in the adoption of energy conservation practices. Agric. Update, 13(2): 188-191; DOI : 10.15740/HAS/AU/13.2/188191. Copyright@2018: Hind Agri-Horticultural Society. 